Статья посвящена анализу состояния современного гуманитарного образования. На основании исследования основных условий развития российской системы образования определены причины необходимости разработки новых федеральных государственных образовательных стандартов, их преимущества и недостатки. Особо отмечено, что коммуникационное общество в целом актуализирует проблематику субъект-субъектных отношений в социальной сфере и, соответственно, повышает значимость решения всех проблем образования в общей логике развития страны. При этом значима обратная детерминация: субъект образовательного процесса влияет на состояние тех социальных сфер, в которые включен. В этой связи высказывается предположение, что в настоящее время система образования представляет собой диалектическое единство генерации знания и процессов управления им. В этом контексте предпринята попытка концептуализации основных рисков гуманитарного образования. Показана значимость междисциплинарных исследований особенностей критической рефлексии, лингвистического поля субъекта, состояния академического знания. Очерчены основные контуры минимизации выделенных рисков развития образования.

Ключевые слова: образование, субъект, риск, генерация знания, управление знаниями, рефлексия, лингвистика, умения

\title{
Knowledge Management and Knowledge Regenerating: Main Risks of Modern Liberal Arts Education
}

The article is devoted to analyzing the status of modern liberal arts education. Based on research of Russian educational system development general conditions, prerequisites to necessary development of new federal governmental educational standards, their advantages and disadvantages, are have been identified. It is particularly stressed that communicative society as a whole actualizes the problematic of subject-subjective relationships in social sphere and accordingly increases the meaningfulness of solving all educational problems within general logic of country development. In this event, the reverse determination is meaningful: the subject of educational process impacts on the status of those social spheres, in which he is incorporated. In this connection, the estimation is expressed that presently the educational system represents the dialectical unity of generating knowledge and the processes of regulating them. In this context, the attempt is undertaken to conceptualize main risks of liberal arts education. The meaningfulness of interdisciplinary investigations is shown on critical reflection peculiarities, subject's linguistic field, status of academic knowledge. Main contours of minimizing the accentuated risks in education development are outlined.

Key words: education, subject, risk, knowledge generating, knowledge regulating, reflection, linguistics, skills 
к формированию навыка, его суть противоположна любой формулировке компетенции, так как компетенция в любом случаем остается на уровне рассудочной рациональности, тогда как результат гуманитарного образования, так или иначе, ориентирован на развитие творческих способностей. Гранью проявления этого скрытого конфликта служат требования стандарта среднего образования о формировании у обучаемого критического мышления, а в системе высшего образования в формулировке универсальных мировоззренческих компетенций. Однако реальное сужение поля гуманитарного знания в общей системе генерации знаний затрудняет последующее адаптивное управление знаниями у субъекта и одновременно детерминирует особую значимость анализа возможных рисков раскрытия гуманитарного знания в образовательном процессе.

Методология исследования ного процесса: вместо обязательного минимума некоторой суммы знаний от выпускника всех ступеней обучения требуется универсальное умение учиться. Собственно компетентностный подход ориентирован на подготовку специалиста, умеющего адаптироваться к изменяющимся условиям профессиональной деятельности через самостоятельное овладение новыми компетенциями [13]. Общей ориентацией всех педагогических практик становится модель интерактивного обучения и постепенный отказ от традиционных моделей пассивного и активного обучения. Соответственно, любые проблемы современного образования и в мире, и в России коренятся в особенностях и закономерностях субъект-субъектных отношений, что с необходимостью актуализирует гуманитарные исследования. Другой особенностью образовательного поля является непосредственная включенность образования в общие управленческие закономерности развития общества, которые детерминируются усилением процессов глобализации и интегративных тенденций в культуре [14]. Управленческие задачи также обнаруживают необходимость обращения к гуманитарной сфере знания. Наконец, коммуникативные процессы в обществе существенно меняют самого субъекта образовательного процесса, который в реализации собственной свободы в процессах обучения все чаще попадает в ситуации конфликта с предлагаемой моделью управления этих процессов. В свете этого сегодня особо актуальной представляется проблема исследования трансформаций системы взаимосвязи генерации знаний и особенностей управления знаниями современного субъекта образования. Наиболее остро эта проблема стоит в сфере гуманитарного знания, так как в основании развития последнего лежит скрытый конфликт с общей стратегией развития образовательного института. Гуманитарное знание никоим образом не может быть сведено

Обозначенная проблематика носит междисциплинарный характер и детерминирует необходимость применения в ее анализе наиболее универсальных методов. Определение предмета исследования опирается на применение метода от абстрактного к конкретному, что позволяет в качестве исходного элемента анализа констатировать коммуникативного субъекта, где гносеологические характеристики находятся в тесной взаимосвязи с характеристиками социальными. Последние не сводимы к гендерным или социальным свойствам, а предполагают диалектическое единство субъекта речи, рассказа, действия и ответственности. В выделении отдельных элементов системы взаимосвязи генерации знаний и процессов управления ими наиболее эффективным становится структурный подход. Так как современный образовательный процесс представляет собой единство педагогической теории, практики и эксперимента, то структурно-функциональный подход неразрывно связан с системным. Системный подход позволяет определить наиболее оптимальный вариант решения проблемы среди возможных альтернатив. В анализе современного коммуникационного субъекта необходимо обращение к элементам синергетического подхода. В частности, адекватное изучение процессов генерации и управления знаниями основано на признании всей системы образования сложноорганизованным феноменом, носители которого многовариативны в собственной реализации. Наиболее актуальным представляется выделение определенных точек бифуркации в современном образовательном процессе в виде наиболее острых точек риска развития гуманитарного образования с целью формирования эффективной стратегии управления процессов генерации знания. 
Данная методология позволяет определить в качестве объекта исследования особенности коммуникативного субъекта образования. Предметом предлагаемого анализа становится область особенностей генерации знаний и специфики управления ими в аспекте раскрытия основных рисков гуманитарного образования.

Гипотеза исследования

На развитие современного образовательного процесса в целом и, особенно, на степень его эффективности влияет единство генерации знания и управления ими. В настоящее время противоречие между этими процессами имеет тенденцию перерождения в конфликтное состояние. Причинами, детерминирующими такое состояние, и одновременно следствиями такого условного "разрушения» субъекта образовательного процесса являются объективные риски развития гуманитарной сферы знания. В качестве основных рисков следует определить нарушение процессов критической рефлексии современного субъекта образования; лингвистическую перестройку коммуникационных потоков и, как следствие, лингвистическую неопределенность субъекта образования; универсализацию знания-навыка и замена им знания академического; кризисные явления в аксиологической сфере образования; отсутствие четкой модели корреляционных связей между процессами генерации знания и механизмами управления ими.

Риски формирования рефлективного мышления в обучении

Современное развитие института образования качественно меняет представление о традиционном гносеологическом субъекте, развитие которого всегда стоит в центре образовательных потоков. Нарастание объемов информации и усиление взаимодействия коммуникационных связей детерминирует доминанту рефлексии в процессах генерации знания. В случае нарушения рефлексии или при ее вытеснении из мышления эффективность освоенности знания стремится к нулю [7]. В крайних случаях может произойти растворение субъекта в потоках информации с потерей его реальной идентификации (собственно, весь негатив виртуализации экзистенции современного человека сводится именно к этому явлению) [3]. Именно поэтому современные федеральные государственные образовательные стандарты одним из ключевых требований к образовательному процессу определяют через необходимость формирования навыков критической рефлексии [2]. На практике это требование требует междисциплинарного теоретического анализа с обязательным включением элементов философской методологии. Последняя в анали- зе рефлексии выделяет множество ее видов как познавательной процедуры. В педагогической науке в настоящее время формирование навыка рефлексии вписано в концепции «критического мышления». В определении процессов генерации знания основоположники данной педагогической стратегии (Дж.Л. Стил, К.С. Мередит, Ч. Темпл, С. Уолтер) исходят из того, что субъект образовательного процесса должен стоять «выше» наличной ситуации и уже в процессе «потребления» быть критичным и в отношении собственного Я, и в отношении других Я, и в отношении не-Я [12]. Следует отметить, что в данном допущении, которое в сегодняшней практике образования претендует на статус свершившегося факта, проявляет себя объективная закономерность развития образовательного процесса: при всех тенденциях технизации общества значимость гуманитарного сегмента знания имеет тенденцию возрастать. Необходимость ориентации компетентностного подхода на достижение способности критической рефлексии у субъекта вызвана "бунтом» против абсолютизации исключительно практически ориентированного результата, сведенного к навыку. Вне теоретической академической мобильности субъект образования не встраивается в систему информационного общества, где успешность его профессиональной деятельности напрямую зависит от умения встраиваться в измененную среду. Будучи спорной с точки зрения философии, в педагогической теории, на первый взгляд, концепция «критического мышления» может быть оценена как адекватный ответ на вызовы изменяющегося общества в интеграции генерации и управления знаниями. Сформированное «критическое мышление» лежит в основе навыка достижения результата вне зависимости от конкретного содержания ситуации. Другими словами, субъект выносится за рамки информации[8]. Но неинформативным в условиях коммуникационного общества он быть не может, поэтому выход из складывающейся ситуации только в том, чтобы информативное начало субъекта было управляемым. Это означает, что на самом деле рефлексия заменена другим процессом - формированием. Формой этого процесса определяется интерактивное обучение, а содержание сведено к формированию устойчивого навыка перетасовки информации в зависимости от эффективности ожидаемого результата [16]. Критериально неопределенны основные маркеры критического мышления: способность оценивания, открытость новым идеям, формирование собственного мнения и, собственно, рефлексия собственных суждений. Но главный риск состоит в стремлении заменить процесс творческого мышления навыком. Если в области научного знания это детерминирует неуправляемый рост псевдонаучного сегмента, то в области социальных отношений позволяет говорить о появлении нового социального субъ- 
екта - Ratio Serviens [9]. Такой статус будущего специалиста не только не отвечает запросам современного экономического рынка, но и угрожает общей безопасности и стабильности развития страны, так как Ratio Serviens программируем и управляем. С точки зрения единства генерации и управления знаниями появление Ratio Serviens свидетельствует об остром дисбалансе между означенными процессами. Между тем, современное реформирование образования позволяет восстановить навык управления знаниями в единстве с их постоянной генерацией. Формирование универсальных компетенций призвано реализовывать три основные функции образования: помогать учиться обучаемому, позволять будущим специалистам быть гибкими к запросам работодателей и, наконец, позволять быть успешным в дальнейшей жизни. Теоретический анализ компетентностного подхода убедительно показывает, его инновационное стремление проверять сформированность компетенций, а не сумму знаний, в сущности отражает прежние традиции российской высшей школы. Педагог не «кормит» знаниями, а «ведет» за собой, когда ученик открывает знание в себе. Творчески игровое преподавание гуманитарных дисциплин не позволит превратить мышление в навык, а. напротив, навыки, формируемые в процессе генерации знания, становятся способными превратить мышление в критическое. Критическая рефлексия, в свою очередь, в генерации знания откроет субъекту пути управления ими [2]. Педагогические модели и стратегии могут быть самыми разными - от тактических до стратегических. Это детерминирует многообразие конкретных форм и приемов. В частности, эффективность СРС (самостоятельной работы студентов), чей сегмент, согласно требованиям ФГОС имеет тенденцию увеличиваться в объеме, напрямую зависит от маркеров ее границ, определяемых вузом. В ФГБОУ ВО «МГТУ им. Г.И.Носова» используется включение гуманитарного анализа в организацию СРС вне зависимости от содержания дисциплины. Гуманитарные стратегии определены в двух основных направлениях: систематизация интеллектуального поведения студента в процессе обучения с целью более быстрого, эффективного усвоения знания и привитие навыка переработки информации, стратегии понимания, умения сохранения информации. В целях достижения единства генерации знания и эффективности управления используются метакогнитивные, когнитивные, компенсаторные и стратегии сотрудничества. В механизмах обучения наибольшую эффективность показывает привлечение к процессам очного обучения и непосредственному контакту с преподавателем элементов курсов дисциплин в формате on-line. Обучаемый, в процессе сравнения читаемого в аудитории курса с курсами аналогичных дисциплин, предложенными, например, на платфор- мe openedu.ru, не только критически генерирует знание предмета, но и обретает навык управления информацией в целях наиболее эффективного понимания материала.

Лингвистические риски генерации и управления знаниями

Современное образование развивается в условиях измененной формы существования культуры. Культура сегодня в силу противоречивых процессов глобализации полидиалогична и полиязычна [1]. Это позволяет говорить о коммуникациях как некоторой универсальной субстанциональной основе всех социальных отношений. Соответственно в структуре субъект-субъектных отношений сферы образования происходит, прежде всего, коммуникационный сдвиг. Помимо традиционных форм диалога педагога с собственным мировоззренческим основанием, с парадигмой педагогической науки в процессе обеспечения процедуры знания он постоянно снимает в себе обостренный конфликт мировосприятия между собственным поколением и поколением обучаемых. Обучаемый в последнее время оказывается погруженным в формы виртуального диалога, который имеет свои закономерности развития, существенно отличающиеся от привычных форм «живого» диалога [17]. Эти тенденции нарушают процесс непосредственного диалога между двумя автономными субъектами образовательного процесса. В результате нарушена диалектика прерывности и непрерывности в генерации знания. «Потребление» знания становится фрагментарным. Процессы управления имеют тенденцию вытеснения процессами манипуляции. Субъекты условно становятся лишними в процессе обучения, выносятся за его рамки. Образование сведено к процессу функционирования информации ради самой информации. На практике это приводит к острым негативным последствиям в развитии страны. В частности, экономический рынок до сих пор испытывает трудности вследствие несоответствия системы высшего образования требованиям к качеству человеческого капитала [14]. Ситуация осложняется тем, что помимо процедуры диалога существенно трансформируется способ раскрытия культурных феноменов и институтов, в частности, в области образования [1]. Он становится поликультурным. Само понимание поликультурности сегодня теоретически неопределенно. Зачастую «поли» сводится либо к многовариативности чего-либо, либо к многоуровневости, то есть понимается в рамках либо горизонтального структурирования, либо в выделении вертикальных структур. Однако эффективность структурного подхода в анализе данной особенности образования минимальна. Коммуникационный субъект целостен, как самоорга- 
низующаяся сложная система весьма подвижен. В его движениях доминирует вероятностно-случайные закономерности, проявленные в процессе реализации его свободной воли. Поэтому для эффективного преодоления трудностей в современных процессах генерации знания необходимо найти четкие точки бифуркационного разделения единого процесса на множество векторов развития. В преподавании конкретных дисциплин такие точки будут иметь свою специфику и могут не совпадать. Но между ними существует нечто общее, которое снимается в гуманитарном знании. Такая универсализация связана с общей тенденцией доминирования роли языка в коммуникационных процессах [1].

Специфика современного образовательного процесса состоит в том, что знания генерируются не в монополе родного естественного языка, а в условиях полиязычного поля. Субъект образования сегодня погружен не только в привычную область сленгов различных социальных групп, диалектов, пограничных переплетений близлежащих естественных языков, но и находится в сфере экспансии английского языка, который все больше претендует на язык универсального общения [19]. Помимо этого на статус межкультурного коммуникатора претендует наука и ее языки. Сегодня уже автономны в своем развитии и воздействии на человека языки технических гаджетов, которые когда-то были скромной частью искусственных языков науки. И, наконец, набирает силу развитие Интернет-сленгов. В результате система образования является зеркалом общего состояния социальных коммуникаций, где сегодня нарушено понимание информации вследствие засилья иностранных слов в родном языке, постоянного умножения разновидностей молодежного сленга, «традиционности» нецензурной лексики. Наиболее опасны риски утраты в генерации знания самого я субъекта [19]. Гранями этого выступают наблюдаемые в образовательном процессе затруднения понимания речи, когда обучаемый стремится заменить процесс усвоения знания простым считыванием информации. В результате в генерации знания полностью вытесняется, например, навык понимания подтекста знания. Управление знаниями заходит в тупик вследствие объективно возникающих затруднений при воспроизводстве речи. Субъект оказывается не в состоянии выбрать формулировку и определить выражение мысли, тем самым, неизбежно попадая в ситуацию некоторой зависимости от полученной информации.

О значимости гуманитарного знания для преодоления этих негативных тенденций косвенно свидетельствует то, что даже в сегменте российского образования становится привычное обозначение гуманитарного образования как liberal arts education. В этом ключе представляется важным говорить о так называемом общем гуманитарном образовании, дисциплины которого, как правило, закреплены в базовой части ФГОС [13]. Общий гуманитарный фундамент в генерации знаний привычен в системе образования. Традиционно и то, что его пропорции и содержание напрямую зависит от общего духа конкретной исторической эпохи. Но сегодня главным выступает не количество часов, и даже не измененный перечень дисциплин. В практике социальной жизни существенно изменен запрос в отношении этого сегмента генерации знания. Его функции теперь не в определении некоторого устойчивого основания последующего построения картины теоретического конструирования мира, а в формировании личностных навыков, которые смогут впоследствии повысить эффективность освоенности профессиональных знаний. Так, общая гуманитарная подготовка должна обучать способам адаптивной операции с информацией. Например, обучаемый должен уметь отслеживать трансформации содержания информации в зависимости от способа ее передачи.

Соответственно через общую гуманитарную подготовку обучаемый должен владеть правилами работы со словарным запасом языка.

Риски универсализации знания-навыка и замены им знания академического

Данные риски гуманитарного образования возникают в сфере так называемого специализированного образования и связаны, прежде всего, со спецификой рациональности в сфере гуманитарного знания. Однако сегодня сфера таких рисков имеет тенденцию расширяться и постепенно выходит за привычные рамки. Об этом свидетельствует формирование концепции soft skills и попытки внедрения ее даже в области рабочих специальностей. Само определение области soft skills достаточно неопределенно. При обобщении характеристик можно «мягкие или гибкие» навыки определить через сведение к критическому мышлению, эффективным коммуникациям, умению обрабатывать информацию как с академической, так и с культурологической точки зрения, анализировать количественные и качественные данные. Данные требования к результатам образования детерминированы объективным социальным фактором. Изменение экономического рынка сегодня не позволяет будущему специалисту рассчитывать на однозначный, четко определенный путь карьерного роста [14]. Отсутствие предопределенного планирования возможно заменить исключительно способностью эффективного управления знаниями в целях реализации возможности их последующей творческой генерации. Уже это характеризует soft skills в качестве некоторой универсальной базы hard skills и может рассматриваться в качестве весомого аргумента в пользу необходимости и востребованности гу- 
манитарного образования. Однако на практики любые концепции skills подрывают фундамент гуманитарного знания. Знание-навык и знание теоретическое в своей способности взаимодействия с субъектом и в перспективных процессах управления принципиально отличны. Hard skills - это конкретные умения конкретной операции. Понятно, что в условиях постоянно изменяющегося рынка такие навыки менее всего ценны. Но отсутствие маркеров и критериев эффективности soft skills превращают эту область в бесконечное сплетение тренингов, ни содержание которых, ни форма проведения не имеют ничего общего с заявленными умениями критически мылить, адаптацией к коммуникациям и так далее. О кризисе этой части гуманитарного образования косвенно свидетельствует отсутствие эффективности от обучения в большинстве предлагаемых тренингов. Более того, в отношении коммуникативного субъекта можно говорить сегодня о новой форме зависимости - тренинговой, соответственно в области образования модернизируется феномен «вечного студента». Отличие его в том, что у субъекта вытесняется не только результативность обучения в пользу бесконечного процесса, но и сам процесс генерации знания уходит на второй план. Его заменяет ожидание эмоционального состояния от обучения. Тем не менее, формирование социально-психологических навыков возможно, но исключительно в сфере академического знания гуманитарного образования. Безусловно, такие навыки могут быть сформированы косвенным образом только в проведении проектных практических занятий с использованием методов кейс-stady в процессе традиционной генерации знаний. Наиболее адаптивными в этом случае представляются следующие методики, предлагаемые современной педагогической наукой: методы анализа ситуаций, имитационных упражнений, тренингов, методы разыгрывание ролей, мозговой штурм, МАСТАК-технология (метод активного социологического тестирования, анализа и контроля). Это позволит снять конфликт между вербальной и невербальной коммуникацией у современного субъекта и, тем самым, сформировать интерес к генерации академического знания [7]. В свою очередь, это позволить оптимизировать процедуру управления знаниями.

Риски отсутствия корреляции генерации и управления знаниями, вызывающие кризисные явления в аксиологической составляющей

образования

Риски отсутствия корреляции генерации и управления знаниями наиболее наглядны в уровне рассмотрения образования как целостной социальной организации. Поэтому данная проблематика выходит в смежные теорети- ческие области, в частности, в область теории менеджмента. Основанием анализа выступает невозможность автономной генерации определенного вида знания в условиях нарастания интегративных процессов в коммуникациях. Необходим системный, комплексный подход ко всему многообразию существующих видов знаний, с одновременным выстраиванием определенной цепочки: знания отдельного индивида - знания организации (в том числе и образовательной) знания общества. При этом налицо синергетический эффект, подразумевающий, что каждый из предшествующих элементов цепочки суммируясь друг с другом образует последующий элемент и движение происходит по нарастающей вверх [4], образуя или продуцируя «новые знания» и способствуя существенному расширению доступа к знаниям. Тем самым, в настоящем трансформирована процессуальная форма субъект-субъектных отношений в образовательной сфере. Возникает проблема обратной связи. С ней могут столкнуться как отдельные индивидуумы в процессе обучения так и само образование как организация: отсутствие соответствующих умений и навыков использовать имеющиеся знания в их абстрактном и конкретном, теоретическом и практическом виде, а также продуцировать новые знания. В данном аспекте управление знаниями тесно взаимосвязано с процессом генерации знаний (являясь взаимосвязанными инновационными родовыми понятиями, они в тоже время требуют четкого разграничения) [5; 6]. Под управлением знаниями понимается совокупность действий, необходимых для создания внутри организации условий, позволяющих работникам применять, развивать и консолидировать все необходимые знания и навыки, а также обмениваться ими [11]. Тогда как, генерация знаний трактуется как получение интеллектуальных результатов, обладающих высокой степенью новизны, базирующихся на имеющейся в наличии информации; «узкоспециализированный процесс, где выходными составляющими становятся новые знания, выступающими одновременно и вспомогательными факторами» [15]. При этом необходимо отметить (и что тоже может вызвать определенный риск), что новое знание может быть получено или генерировано только тогда, когда имеется основа/ фундамент в виде предыдущего понимания. Здесь налицо может возникнуть риск в отнесении этапов к каждому процессу. Процесс управления знаниями, чаще всего, представляется в виде последовательности следующих действий: накопление информации кодификация - анализ - улучшающая модификация - обратный синтез. Этапы генерации знаний в чем-то схожи со схемой управления знаниями: знания, включая неформализованные - критический анализ проблемы, включая ее концепцию идея, рекомбинирующая проблему - творческий синтез [5; 15]. Общая цель процессов заключа- 
ется в применении инновационных стратегий и эффективных методов, позволяющих гибко реагировать на новые экономические, социальные, политические или культурные условия и удовлетворять потребности в получении новых знаний $[10 ; 18]$. Взаимосвязь данных интеллектуально-управленческих процессов предполагает наличие аналитических способностей и компетенций у участников образовательного процесса, а также применение методов, активизирующих творческое и критическое мышление.

Результаты исследования

В ходе исследования процессов единства генерации знаний и управления ими обнаруживаются риски гуманитарного образования сегодня. Эти риски не исчерпываются видимым сокращением часов на гуманитарные дисциплины и вытеснением их из перечня дисциплин стандартов. Основные риски заложены либо в противоречивых требованиях ФГОС, либо в упрощенном толковании нормативного содержания образования. Анализ современной ситуации позволяет в качестве основных рисков гуманитарного образования определить деструкцию рефлексии субъекта; лингвистическую трансформацию обучаемого; кризис академического знания; перестройку системы ценностей в образовании; разрыв между усвоением знания и управлением. Тем не менее, изучение проблемы убедительно демонстрирует, что большинство рисков можно избежать или минимизировать их последствия. Так, формирование критической рефлексии возможно при грамотной реализации компетентностного подхода, где в личном общении с преподавателем обучаемый не просто генерирует предметное знание, но и определяет основания управления последующей адаптации своей профессиональной компетенции через развитие навыков анализа, планирования, регулирования и оценки собственной деятельности. Негативные последствия лингвистических атак в отношении субъекта образования гуманитарное знание может минимизировать через развитие общекультурных компетенций. Основные риски гуманитарного образования в этом случае сводятся к затруднениям в процессах понимания (нарушается целостность процесса генерации знания) и в процессах воспроизводства речи (под угрозой оказывается управление знаниями). Общая гуманитарная подготовка в генерации знаний обучаемого способна привить навык распознавания знака и смысла слова и, тем самым, позволит сформировать у студента психологическую установку на самостоятельное систематическое пополнение своих знаний и выработку умений ориентироваться в потоке информации при решении новых учебных и профессиональных задач. Современное состояние гуманитарного образования способно предотвратить негативные последствия стремления вытеснить академическое знание, что чревато потерей творческого начала специалиста. Адаптивное применение современных педагогических методик позволяет в процессе генерации основ гуманитарного знания сформировать умение коммуникативного обмена информацией. Деятельность в области управления знаниями и генерации знаний должна быть неотъемлемой частью стратегии развития образования и образовательной организации, с переходом конкурентной борьбы на принципиально новый уровень, основной чертой которого является конкуренция «умов/знаний».

Заключение

Современное развитие образования характеризуется многими кризисными чертами, среди которых кризис гуманитарной сферы занимает особое место. Проведенный анализ убеждает в необходимости адаптации процессов генерации и управления знаниями к требованиям измененной среды. Выявление основных рисков гуманитарного образования убедительно демонстрирует наличие скрытых резервов для трансформации процесса обучения, что способно повысить эффективность подготовки будущих специалистов. Логика развития общества диктует повышение интереса к гуманитарной сфере знания, так как образование становится особым информационным потоком, где участвующие субъекты вовлечены в полидиалог, происходящий в поле полиязычия.

ЛИТЕРАТУРА

1. Жилина В. А. Идеологическое управление как сущностная черта развития общества // Социум и власть. 2016. №1 (57). С. 51-55.

2. Жилина В.А. Критическая рефлексия как ключевая составляющая современного образования // Вопросы философии. 2018. № 6. С. 59-65.

3. Жилина В.А. Проблема определения идеологического субъекта // Вестник Челябинского государственного университета. 2009. № 29. С. 44-50.

4. Кузнецова Н.В. Знания как стратегический ресурс развития организации // Мировоззренческие основания культуры современной России : сборник научных трудов IX Международной научно-практической конференции. Выпуск 9. Магнитогорск, 2018. С. 92-95.

5. Кузнецова Н.В. Управление знаниями и генерация знаний: взаимосвязь в процессе профессиональной подготовки управленческих кадров // Фундаментальные и прикладные научные исследования: актуальные вопросы, достижения и инновации: сборник статей X Международной научно-практической конференции. 
В 2 частях. Пенза. 2018. С. 161-163.

6. Кузнецова Н.В. Управление знаниями как один из подходов к повышению качества профессиональной подготовки управленческих кадров // Социосфера. 2015. № 1. С. 86-89.

7. Лазарев Ф.В., Лебедев С.А. Философская рефлексия: сущность, типы, формы // Вопросы философии. 2016. № 6. С.15-29

8. Липовецки Ж. Эра пустоты. Эссе о современном индивидуализме. М.: Владимир Даль, 2001.

9. Пружинин Б.И. Ratio Serviens // Вопросы философии. 2004. № 12. [Электронный pecypc] URL: http:/vphil.ru/ index.php?option=com_content \&task=view\&id=165\&Itemid=55 (дата обращения 1.12.2018)

10. Сепир Э. Избранные труды по языкознанию и культурологии. М.: Прогресс, 2002. 656 с.

11. Сперк Р., Картер Д. Управление знаниями: обзор передового опыта европейских компаний // Деловое совершенство. 2005. № 4. С. 20-30.

12. Стил Дж. Л., Мередит К., Темпл Ч., Уолтер С. Основы критического мышления: междисциплинарная программа. Пособие 1. М.: ИОО, 1999.

13. Холстед М. Орджи Т. Ключевые компетенции в системе оценки Великобритании // Современные подходы к компетентностно-ориентированному образованию: Материалы семинара / под ред. А.В. Великановой. Самара, 2001.

14. Экономические реформы в России. / Абдуллаев Н.А., Астратова Г.В., Кусаинов Т.А., Мусина Г.С., Рущицкая О.А., Борзихина И.В., Благодатских В.Г., Коноплева Л.А., Ветошкин А.П., Пугин С.В., Воронин Б.А., Донник И.М., Лоретц О.Г., Кот Е.М., Жилина В.А., Князев В.М., Журавлева Л.А., Кружкова Т.И., Лавров В.Н., Михалев А.В. и др.. Екатеринбург, 2017.

15. Янсен Ф. Эпоха инноваций : пер. с англ. М.: ИНФРА-М, 2002. 308 с.

16. Akhmetzyanova M.P., Zhilina V.A., Teplykh M.S., Chernova E.G., Nazaricheva A.I., Slobozhankina L.R. Cognitive faith as an attributive phenomenon of cognition // Man in India. 2017. T. 97. no. 14. pp. 329-339.

17. Chernova E.G., Zhilina V.A, Akhmetzyanova M.P., Teplykh M.S., Nazarycheva A.I., Prilukova E.G. Maxims of Dialogic Interaction in the Effective Negotiation Practice // Modern Journal of Language Teaching Methods. 2018. T. 8. no.1 pp.122-129.

18. Sadler D.R. Three in-course assessment reforms to improve higher education learning outcomes // Assessment and Evaluation in Higher Education. 2016. 41 (7), pp. 1081-1099. DOI: 10.1080/02602938.2015.1064858

19. Slobozhankina L.R., Teplykh M.S., Akhmetzyanova M.P., Zhilina V.A., Nazaricheva A.I. Self-knowledge as a criterion for classifying philosophical doctrines // XLinguae. 2018. Vol. 11, Iss. 2. pp. 437-444.

REFERENCES

1. Zhilina V. A. Ideological management as an essential feature of the development of society. Socium and power. 2016. no. 1 (57). pp.51-55. (in Russian)

2. Zhilina V.A. Critical reflection as a key component of modern education. Voprosy filosofii - Questions of Philosophy. 2018. no. 6. pp. 59-65. (in Russian)

3. Zhilina V.A. The problem of determining the ideological subject. Bulletin of the Chelyabinsk State University. 2009. no. 29. pp. 44-50. (in Russian)

4. Kuznetsova N.V. Knowledge as a strategic resource for the development of the organization // Worldview grounds of the culture of modern Russia: a collection of scientific papers of the IX International Scientific and Practical Conference. Issue 9. Magnitogorsk, 2018. pp. 92-95. (in Russian)

5. Kuznetsova N.V. Knowledge management and knowledge generation: interrelation in the process of professional training of managerial personnel // Fundamental and applied scientific research: topical issues, achievements and innovations: collection of articles of the X International Scientific Practical Conference. In 2 parts. Penza. 2018. pp. 161-163. (in Russian)

6. Kuznetsova N.V. Knowledge management as one of the approaches to improving the quality of professional training of managerial personnel. Sociosphere. 2015. no. 1. pp. 86-89. (in Russian)

7. Lazarev F.V., Lebedev S.A. Philosophical reflection: essence, types, forms. Voprosy filosofii, 2016. no. 6. pp. 15-29 (in Russian)

8. Lipovetsky J. Era of emptiness. Essay on modern individualism. Moscow, Vladimir Dal Publ., 2001. (in Russian)

9. Pruzhinin B.I. Ratio Serviens. Voprosy filosofii - Questions of Philosophy. 2004. no. 12. Available at: http: /vphil.ru/ index.php? Option = com_content \& task = view \& id = 165 \& Itemid = 55 (accessed 1 December 2018) (in Russian)

10. Sapir E. Selected Works on Linguistics and Cultural Studies. Moscow, Progress Publ., 2002. 656 p. (in Russian)

11. Spark R., Carter D. Knowledge Management: A Review of European Companies Best Practices. Business Excellence. 2005. no. 4. pp. 20-30. (in Russian)

12. Steele JL, Meredith K., Temple H., Walter S. Fundamentals of Critical Thinking: an interdisciplinary program. Manual 1. Moscow, PSI Publ., 1999. (in Russian)

13. Halsted M., Orji T. Key Competences in the UK Assessment System // Modern Approaches to Competency-Oriented Education: Workshop Materials / ed. A.V. Giant. Samara, 2001. (in Russian)

14. Economic reforms in Russia. / Abdullaev N.A., Astratova G.V., Kusainov T.A., Musina G.S., Rushchitskaya O.A., Borzikhina I.V., Blagodatskikh V.G., Konopleva L.A., Vetoshkin A.P., Pugin S.V., Voronin B.A., Donnik I.M., Loretz O.G., Kot E.M., Zhilina V.A., Knyazev V.M., Zhuravleva L.A., Kruzhkova T.I., Lavrov V.N., Mikhalev A.V. and others. Ekaterinburg, 2017. (in Russian)

15. Jansen F. The Epoch of Innovation: Tr. from English. Moscow, INFRA-M Publ., 2002. 308 p. (in Russian)

16. Akhmetzyanova M.P., Zhilina V.A., Teplykh M.S., Chernova E.G., Nazaricheva A.I., Slobozhankina L.R. Cognitive faith 
as an attributive phenomenon of cognition. Man in India. 2017. V. 97. no. 14. pp. 329-339.

17. Chernova E.G., Zhilina V.A, Akhmetzyanova M.P., Teplykh M.S., Nazarycheva A.I., Prilukova E.G. Maxims of Dialogic Interaction in the Effective Negotiation Practice. Modern Journal of Language Teaching Methods. 2018. V. 8. no.1 pp. 122-129.

18. Sadler D.R. Three in-course outcomes. Higher Education. 2016. 41 (7), pp. 1081-1099. DOI: 10.1080/02602938.2015.1064858

19. Slobozhankina L.R., Teplykh M.S., Akhmetzyanova M.P., Zhilina V.A., Nazaricheva A.I. Self-knowledge as a criterion for classifying philosophical doctrines. XLinguae. 2018. Vol. 11, Iss. 2. pp. 437-444.

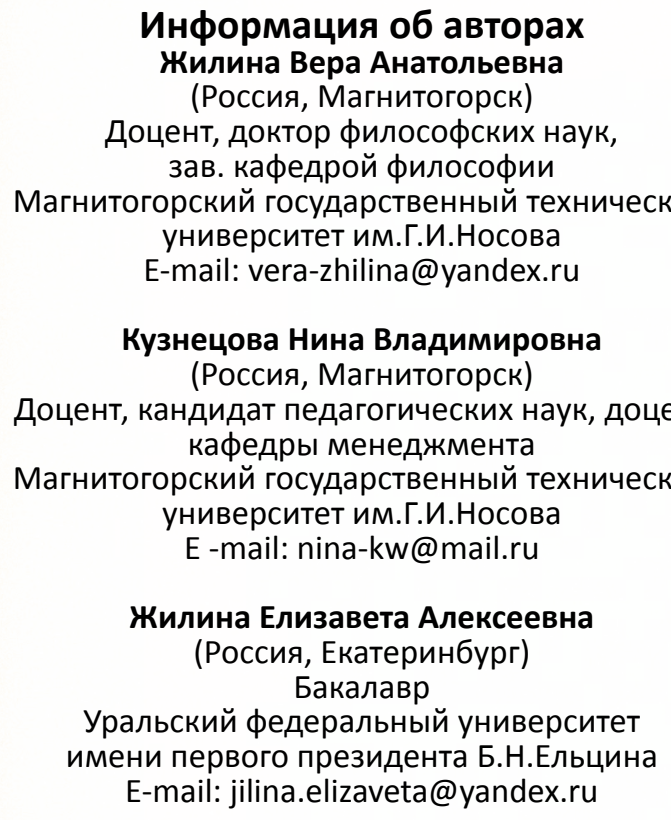

Ссылка для цитированиягост

Жилина В. А., Кузнецова Н. В., Жилина Е. А. Управление знаниями и генерация знаний: основные риски современного гуманитарного образования // Перспективы науки и образования. 2018. № 6 (36). C. 18-26. doi: 10.32744/pse.2018.6.2

\section{Information about the authors Vera A. Zhilina}

(Russia, Magnitogorsk)

Associate Professor,

Doctor of Philosophical Sciences,

Head of the Department of Philosophy Nosov Magnitogorsk State Technical University

E-mail: vera-zhilina@yandex.ru

Nina V. Kuznetsova

(Russia, Magnitogorsk)

Associate Professor, $\mathrm{PhD}$ in Pedagogical Sciences,

Associate Professor of the Department of Management Nosov Magnitogorsk State Technical University

E-mail: nina-kw@mail.ru

Elizaveta A. Zhilina

(Russia, Yekaterinburg)

Bachelor

Ural Federal University

named after the First President of Russia B. N. Yeltsin E-mail: jilina.elizaveta@yandex.ru

\section{For Reference ${ }^{\mathrm{APA}}$}

Zhilina, V. A., Kuznetsova, N. V., \& Zhilina, E. A. (2018). Knowledge management and knowledge regenerating: main risks of modern liberal arts education. Perspektivy nauki i obrazovania-Perspectives of Science and Education, 36 (6), 18-26. doi: 10.32744/pse.2018.6.2. (In Russ., abstr. in Engl.) 